\title{
The invasive management of angina: issues for consumers and commissioners
}

\author{
David Gunnell, Ian Harvey, Lee Smith
}

\begin{abstract}
Objective - To review, from the purchaser's perspective, the current state of knowledge of techniques for investigation and treating coronary artery disease. The study was based on evidence from past and continuing randomised controlled trials (RCTs).
\end{abstract}

Criteria for inclusion of reports - Articles listed on Medline (1990-3) with the keywords coronary disease, angina, and unstable angina (combined with surgery, economics, therapy, or drug therapy) and percutaneous transluminal coronary angioplasty (PTCA) and coronary artery bypass grafting (CABG) were included. Articles published before 1990 were obtained from two comprehensive literature reviews published by the Rand organisation in $1991^{12}$ and from the papers obtained using the Medline search. A hand search of relevant journals published between July 1993 and June 1994 was also undertaken. Results from more recently published RCTs are included.

Results - CABG provides improved angina relief compared with drug treatment and may prolong life in patients with more severe illness. PTCA is also better than drug treatment, but less so than CABG, and its cost advantages over CABG decrease with time. Repeat intervention for return of symptoms is more frequently required after PTCA, but increasing numbers of patients are also undergoing second and third repeat CABG for graft occlusion in the years after the original operation. Newer PTCA techniques are not, as yet, fully evaluated. One technique, atherectomy, has been shown to be no more effective, and more expensive, than conventional balloon angioplasty. In the short term intracoronary stents reduce the problems associated with vessel occlusion after PTCA and therefore reduce the need for further intervention. PTCA should not be performed without ready access to cardiothoracic support. There is an increasing trend towards the development of coronary catheterisation units at peripheral sites. This may lead to increasing, inappropriate use of this investigation in suboptimal circumstances.
Conclusions - Ischaemic heart disease is an important cause of morbidity and mortality and invasive management techniques are developing rapidly; some service expansion is occurring without trial evidence. More research is required to determine the optimum balance of PTCA, CABG, and angiography and population requirements for these procedures. In the meantime, in the absence of firm long term evidence of the superior cost effectiveness of PTCA compared with CABG, the rapid expansion of this procedure should be limited. Patients should be fully informed of the benefits and disadvantages of CABG and PTCA, where either procedure is indicated, to enable them to make fully informed choices.

(f Epidemiol Community Health 1995;49:335-343)

Ischaemic heart disease (IHD) is the leading cause of death in the United Kingdom and a common cause of morbidity. ${ }^{3-5}$ Increasing rates of invasive procedures (coronary artery bypass grafting (CABG) and percutaneous coronary angioplasty (PTCA)) have coincided with a gradual reduction in age adjusted IHD death rates since the $1970 \mathrm{~s},{ }^{6}$ although it seems unlikely that these procedures have played more than a minor role in the observed decline. ${ }^{7}$

Treatments for IHD consume $2.5 \%$ of NHS expenditure. ${ }^{8}$ If the current (1984) UK target of $300 \mathrm{CABGs}$ per million population per year is met, the annual bill will be in excess of £60M. ${ }^{9}$ This target level has now been met in many areas and various authorities suggest that higher target levels may be appropriate. ${ }^{10}$ In addition 8459 PTCAs (costing approximately $£ 3000$ each) were performed in the UK in 1990. ${ }^{11}$

There is striking variation in these intervention rates. ${ }^{12}$ The UK Clinical Standards Advisory Committee reported a twofold inter regional variation in NHS CABG rates and a fourfold variation in PTCA. International variations are even more marked. ${ }^{1113-15}$ The CABG rate in the United States was four times that in the UK in 1991, and that for PTCA eight times higher. This variation greatly exceeds the likely variation in disease incidence and thus provides strong presumptive evidence of sig- 
nificant clinical uncertainty, although unmet need may partly account for this. There is currently no clear evidence on the population incidence and prevalence of angina that is unresponsive to maximal medical treatment or the incidence of angiographically proved IHD associated with lesions for which PTCA or CABG are of proven benefit.

Guidelines on the appropriate use of CABG, PTCA and angiography have been produced by, among others, the British Cardiac Society and the American College of Cardiology and American Heart Association (ACC/AHA). ${ }^{16} 17$ One UK audit that compared practice with guidelines has indicated that $21 \%$ of angiographies and $16 \%$ of CABGs may be inappropriate. ${ }^{18}$ Studies from the United States suggest that PTCA, judged against consensus criteria, is particularly prone to inappropriate use. ${ }^{19-21}$

The goal of rational purchasing is impeded by a number of factors. The first is the emergence of new, largely unevaluated interventions, which include vibrational coronary angioplasty, ${ }^{22}$ the use of lasers, ${ }^{23}$ and rotablators. ${ }^{24}$ Results from randomised trials of atherectomy and stenting have recently been published. ${ }^{25-28}$ Even PTCA, although widely adopted, has not until recently been comprehensively evaluated in randomised studies, although several are now in progress and interim results have been published. ${ }^{29-33 .}$ Secondly, the experimental evidence comparing CABG with medical treatment dates from $1970 \mathrm{~s},{ }^{34-36}$ since when there have been changes in both surgical techniques (such as use of internal mammary artery grafts) and medical treatments (routine use of aspirin and calcium antagonists). The participants in these trials were largely men aged less than 65 , thus restricting the extrapolation of the results to women and older age groups. Lastly, most trials published have failed to incorporate rigorous health economic components.

Against this backdrop this review has three main objectives: to summarise current research of effectiveness and cost effectiveness; highlight gaps in the research record; and address specific issues surrounding the performance of coronary angiography and PTCA in units without cardiac surgical standby.

\section{Effectiveness of CABG and PTCA}

CABG and PTCA are mainly undertaken in the UK for the treatment of stable and unstable angina. An increasing proportion are repeat procedures. ${ }^{37-39}$ The cornerstone of acute infarct management is thrombolytic therapy. Although PTCA is being increasingly used in the USA in the acute phase, any slight advantage $^{40-42}$ is arguably outweighed by the cost of making it available in all units. ${ }^{43}$ IHD patients may sensibly be subdivided according to the type and severity of symptoms, ejection fraction, and the site and number of coronary arteries involved. The four coronary arteries whose occlusion may be identified angiographically are the right coronary, the left main, and its two branches the circumflex and left anterior descending arteries. Randomised controlled trial evidence comparing medical, surgical, and PTCA treatments for each subgroup is not available.

\section{CABG}

Randomised controlled trials in the 1970 s showed that overall in stable angina, CABG provides symptomatic relief in $49 \%$ of patients at one year, compared with $15 \%$ of those treated medically. ${ }^{2}$ At five years these differences narrow to $36 \%$ and $21 \%$ respectively and there is little difference at 10 years. In certain subgroups (those with left main coronary artery disease; those with reduced ejection fraction and two or three vessel disease; left anterior descending artery disease if part of two or three vessel involvement) life expectancy is also improved. A recent overview of trials randomising patients to CABG or medical management showed significant overall reductions in mortality at five and 10 years in those treated surgically $(10 \cdot 2 \% \quad v \quad 15 \cdot 8 \%$ mortality at five years; $26.4 \%$ v. $30.5 \%$ at 10 years). Although in some subgroups of patients no significant effect on mortality was observed. Differences in symptom relief and mortality between medically and surgically treated groups diminish gradually with time. Some of this convergence is because a considerable proportion of those randomised to medical treatment subsequently underwent CABG for symptomatic control and graft occlusion occurred in others randomised to surgery. CABG does not reduce the subsequent incidence of acute myocardial infarction or enable more patients to return to work. ${ }^{234-3644-57}$

In unstable angina, CABG provides improved symptom relief and improved survival to those with three vessel disease and those with low ejection fractions $(<0.5)$ regardless of vessel involvement. ${ }^{58-63}$

PTCA

PTCA requires a shorter hospital stay than CABG and permits more rapid convalescence. ${ }^{10}$ In some centres it is being conducted on an outpatient basis in selected patients. ${ }^{64}$ Complications include an in hospital mortality of $0.4 \%$ and requirement for emergency $\mathrm{CABG}$ in $2-4 \% .^{1}$ Ninety per cent of lesions are successfully dilated but $20-40 \%$ reocclude by one year. These complications are more common with particular anatomical lesions and in patients with unstable angina, multivessel disease, or where operators are less experienced. ${ }^{65-69}$

In a comparison of PTCA and medical treatment for angina patients with single vessel disease (ACME study), ${ }^{70} 64 \%$ in the PTCA group and $46 \%$ in the medical group were angina free at six months $(p<0 \cdot 01)$. Exercise treadmill time was significantly greater in the PTCA arm. Sixteen of 105 patients in the PTCA arm required repeat PTCA, and seven required CABG. In the medically treated arm, 11 subsequently underwent PTCA. There was one death in the medical treatment arm of the 
trial. The conclusion was drawn that, for single vessel coronary artery disease, PTCA offered earlier and more complete relief of angina and improved exercise tolerance, but at the cost of a higher subsequent invasive intervention rate. A second trial of PTCA versus medical treatment (RITA II), incorporating a health economic evaluation, is currently underway.

\section{CABG VERSUS PTCA (FOR SUMMARY OF RECENT} TRIALS SEE APPENDIX A)

A number of randomised controlled trials are currently examining the relative effectiveness of CABG and PTCA ${ }^{71}$ (Appendix A). Recruitment is complete in all of them but follow up is continuing. RITA is a UK based randomised controlled trial and involves 1011 patients with one, two, or three vessel disease. ${ }^{29}$ At 2.5 years there was no significant difference between the two groups' mortality or mortality and acute myocardial infarction combined. Sixteen $(3 \cdot 1 \%)$ patients in the PTCA arm and 18 $(3.6 \%)$ in the CABG arm of the trial had died. CABG offered significantly better angina relief at six months (89\% CABG group symptom free versus $68 \%$ in PTCA group) and at two years $(78 \%$ versus $69 \%)$. In addition, $38 \%$ of those in the PTCA group had either had an acute myocardial infarction, died, or required revascularisation compared with only $11 \%$ in the CABG group $(p<0 \cdot 001)$.

In EAST, the other large randomised trial which has reported medium term (three years) results, 392 patients were randomised to CABG or PTCA. ${ }^{33}$ There was no difference in mortality or the combined outcome of death, acute myocardial infarction, or the presence of large filling defects on thallium scans at three years between CABG and PTCA. Angina, however, was significantly more improved in those who underwent CABG $(88 \%$ v $80 \%$ angina free), although there was no difference in exercise tolerance. Three times more of those treated with PTCA subsequently required repeat revascularisation.

Three other randomised trials have reported outcomes one to two years after randomisation. ${ }^{30-32}$ In GABI the combination of death or acute myocardial infarction occurred more frequently in the CABG arm of the trial $(13.6 \% v 6 \% \mathrm{p}=0.017)$. However, four of the nine deaths in the CABG patients occurred before surgery. Forty four per cent of the PTCA patients required repeat revascularisation compared with only $6 \%$ of those treated with CABG. ${ }^{31}$ The other two trials showed no significant differences in mortality between CABG and PTCA. They too showed that reintervention was required considerably more frequently in those treated with PTCA. Better symptomatic relief was achieved by CABG. ${ }^{30-32}$

A number of observational studies have also provided evidence on this matter. They have failed to show any difference in medium and long term survival between the two treatment categories although symptomatic improvement is more likely with CABG and the need for further intervention is considerably reduced. These advantages of CABG are at the price of a longer stay in hospital and longer postoperative recovery. ${ }^{72-78}$

No randomised controlled trial to date has contained three arms - CABG, PTCA, or medical treatment. Wong et al, using data available up to 1989 , constructed a decision analysis model comparing the relative benefits, costs, and outcomes of these therapies in patients with different disease severity. ${ }^{79}$ They conclude that "revascularisation is not indicated unless severe symptoms, other markers of ischaemia, or severe multivessel disease are present."

\section{NEWER ANGIOPLASTY TECHNIQUES}

Difficulties dilating some obstructive lesions have led to the development of new devices which are both expensive and generally unevaluated. ${ }^{22-24}$ An exception is coronary atherectomy which has been evaluated in two randomised controlled trials - the coronary angioplasty versus atherectomy trial (CAVEAT) and the Canadian coronary atherectomy trial (CCAT).$^{27280}$ In both, the comparison was between one angioplasty technique and another. While hospital costs for atherectomy were significantly greater $(\$ 11904$ versus $\$ 10637$ for angioplasty), there was little difference in six month, event free survival between the two. Twelve month follow up results from CAVEAT show increased mortality in those undergoing atherectomy. Eleven $(2 \cdot 2 \%)$ receiving atherectomy died compared with only $3(0.6 \%)$ of those randomised to PTCA ( $p=$ $0 \cdot 035){ }^{80 a}$

Intracoronary stents (synthetic devices designed to maintain vessel patency) have been developed ${ }^{252681-83}$ to address the problem of restenosis after PTCA. ${ }^{1}$ Two randomised controlled trials have examined their effectiveness compared with traditional PTCA. ${ }^{2526}$ Both trials showed that in the short term (six and seven months' follow up) patients treated with stents required fewer repeat procedures (PTCA or CABG) and clinical outcomes were similar. Length of hospital stay was, however, twice as long and complication rates were higher in those treated with stents. Compared with PTCA for single vessel disease, stenting has an estimated incremental cost effectiveness ratio of $\$ 23600$ per quality adjusted life year, although this varies with different patient groups. ${ }^{84}$ The long term costs, benefits, and risks of these devices are therefore uncertain and in one trial there was a suggestion that the difference between the two treatments diminished towards the end of the follow up period. ${ }^{25}$

\section{Cost effectiveness of invasive procedures}

The most serious current drawback is the lack of a completed randomised controlled trial comparing the cost effectiveness of PTCA and CABG. Economic analyses from RITA after two years of follow up have recently been published; ${ }^{85}$ longer term follow up results will not be available for several years. Other, less robust economic analyses - mainly from the United States - have focused on hospital charges rather than actual economic costs. ${ }^{86}$ 
CABG

The CASS study in the $1970 \mathrm{~s}^{87}$ indicated that in stable angina total inpatient costs in the first year were $\$ 3432$ for medical therapy and $\$ 11100$ for CABG. Both direct (mainly hospital charges and professional fees), and indirect costs (loss in productive capability as measured by loss of income) were measured. CABG is, however, likely to have lower follow up costs. On the effectiveness side of the equation, although long term survival was similar, CABG patients experienced less angina and, by inference, had a better quality of life (see above). A simple expression of cost effectiveness from these data is not, however, possible. Other data have suggested greater cost differences in the first six months after initial angiographic investigation (medical treatment $\$ 5705$; CABG $\$ 27862$ (1977 prices)). ${ }^{88}$

\section{PTCA}

The ACME trial - the only completed randomised controlled trial directly comparing medical therapy and PTCA $^{70}$ - concluded that PTCA offers more relief of angina for onevessel disease but at a higher cost. Formal cost effectiveness ratios were not derived, however. PTCA costs over one year have been reported elsewhere to be five times greater (13625 Dfl $v 2770 \mathrm{Dfl})$ than those of medical treatment but the cost differences diminish with time. ${ }^{89}$ Hospital costs for atherectomy are greater than those for PTCA (see above). ${ }^{27}$ The cost differential between PTCA and stenting is even greater ( $\$ 5396$ versus $\$ 7878)$.

CABG VERSUS PTCA

Analysis of health service costs after two years follow up in the RITA trial show the mean cost of PTCA to be £6916 (SE £235) and for CABG is $£ 8739$ (SE $£ 212$ ) in the London centres (difference $£ 1823$ ( $£ 1202$ to 2404)). The cost difference was smaller $(£ 1050$ (SE $£ 621$ to 1279 ) in the centres outside London. ${ }^{85}$ Whether these differences in costs translate into differences in cost effectiveness and whether these differences diminish with longer

Table 1 Cost/quality adjusted life year (QALY) of competing treatments (adapted from Maynard 199124)

\begin{tabular}{|c|c|}
\hline Treatment & $\begin{array}{l}\text { Cost } / Q A L Y \\
(\mathcal{L}, \text { Aug 1990) }\end{array}$ \\
\hline $\begin{array}{l}\text { Cholesterol testing and diet therapy only (all } \\
\text { adults aged } 40-69)\end{array}$ & 220 \\
\hline Advice from GP to stop smoking & 270 \\
\hline $\begin{array}{l}\text { Neurosurgical intervention for subarachnoid } \\
\text { haemorrhage }\end{array}$ & 490 \\
\hline $\begin{array}{l}\text { Antihypertensive treatment to prevent stroke } \\
\text { (aged 45-64) }\end{array}$ & 940 \\
\hline Hip replacement & 1180 \\
\hline $\begin{array}{l}\text { CABG (left main vessel disease, severe } \\
\text { angina) }\end{array}$ & 2090 \\
\hline Kidney transplant & 4710 \\
\hline Breast cancer screening & 5780 \\
\hline Heart transplantation & 7840 \\
\hline \multicolumn{2}{|c|}{$\begin{array}{l}\text { Cholesterol testing and treatment of all adults } 14150 \\
\text { aged } 25-39\end{array}$} \\
\hline $\begin{array}{l}\text { CABG (1 vessel disease, moderate } \\
\text { angina) }\end{array}$ & 18830 \\
\hline Continuous ambulatory peritoneal dialysis & 19870 \\
\hline $\begin{array}{l}\text { Erythropoietin treatment for anaemia in } \\
\text { dialysis patients (assuming 10\% reduction in } \\
\text { mortality) }\end{array}$ & 54380 \\
\hline
\end{tabular}

$\mathrm{CABG}=$ coronary artery bypass graft. periods of follow up remains to be seen. In ERACI, hospital costs after one year for those treated with CABG were 1.9 times greater than for PTCA. ${ }^{30}$ Economic evaluation from EAST will be published soon. Otherwise only observational data are currently available, which may be invalidated by important case-mix differences. Initial costs of CABG are 1.6 to 2.9 times those of PTCA, although after one year this diminishes to between $1 \cdot 2$ and $1 \cdot 8$, and after five to 10 years there is relatively little difference (PTCA \$26 916; CABG \$32 465 at five years in one study). ${ }^{7989} 97$ PTCA, on the other hand, provides poorer symptomatic relief and reintervention rates are higher (see above).

QUALITY ADJUSTED LIFE YEARS (QALYS)

Cost effectiveness comparisons between invasive cardiological interventions and other competing claims for NHS resources are hampered if a common measure of benefit is not used. The quality adjusted life year (QALY) is widely known as a generic measure for such purposes (see table 1). Unfortunately many cost per QALY figures are based upon estimates of effectiveness rather than robust data from randomised controlled trials and incorporate average rather than marginal figures. ${ }^{9899}$ The survival advantage offered by CABG in those with left main vessel disease is, however, clearly reflected in this table as is the lack of evidence of enhanced survival in those with single vessel disease. $^{100}$

\section{Service delivery issues: PTCA, angiography, and the need for surgical standby}

The main immediate risks of PTCA are acute vessel occlusion, coronary artery rupture, and distal embolisation. In this event three options are available. No action may be taken and the patient may sustain an acute myocardial infarction which is managed in the usual way. Alternatively, redilation or placing of a stent may be attempted. Finally, if the patient is fit and other approaches fail, emergency CABG may be undertaken. It is vital to consider the cost effectiveness of maintaining a cardiac surgical team on constant standby to cover this last eventuality and, further, to assess whether PTCA can safely be performed on sites without surgical back up. ${ }^{101-105}$ In some centres, surgical back up is provided at units geographically separate from the centre where PTCA is performed. One estimate of the cost of on site surgical standby is $\$ 100000$ per patient requiring emergency $\mathrm{CABG}$ (using a $2 \%$ rate of emergency CABG for PTCA). ${ }^{102}$ The opportunity cost is clearly great.

A number of observational studies have examined the effect of delays in intervention on both short and long term outcomes of patients undergoing PTCA. ${ }^{106} 110$ There has been no study with random allocation to PTCA with or without surgical standby. A few case series suggest that, in some instances, immediate access to CABG may have been life saving. ${ }^{11}$ 
Table 2 Advantages and disadvantages of high and low throughput cardiac catheterisation facilities

\begin{tabular}{ll}
\hline $\begin{array}{l}\text { Low turnover, district based cardiac catheterisation facilities, } \\
\text { surgical standby rare }\end{array}$ & $\begin{array}{l}\text { High turnover, cardiac catheterisation facilities based at tertiary } \\
\text { centre, with surgical standby }\end{array}$ \\
\hline $\begin{array}{l}\text { Advantages } \\
\text { 1 Improved access for patient }\end{array}$ & $\begin{array}{l}\text { Advantages } \\
\text { 1 Safer for patient with rapid access to emergency surgery }\end{array}$ \\
2 Familiar surroundings for patient & 2 Possibility of synchronous angiography and PTCA \\
3 Full investigation and work up by local cardiologist & 3 Cardiothoracic surgeon on site to review angiograms \\
4 Improved job satisfaction for cardiologist & 4 Possible economies of scale and the production of \\
5 Shorter waiting list & consistent high quality films with most up to date equipment. \\
Disadvantages & $\begin{array}{l}\text { Disadvantages } \\
\text { 1 Less familiar surrounds for patient and increased anxiety }\end{array}$ \\
1 Reduced operator experience and possible increased & 2 Reduced capacity to communicate with referring \\
2 Distant from surgical support in the event of complications & cardiologist/physician \\
3 High cost of keeping equipment up to date & 3 Time wasted on routine procedures which could be spent \\
4 Need to send films to cardiothoracic surgeon to review & on complex interventions \\
5 If accepted that PTCA cannot be undertaken without & \\
surgical cover, lose opportunity to undertake synchronous & \\
PTCA & \\
6 Tendency to supply led rather than demand led & \\
angiography &
\end{tabular}

PTCA = percutaneous transluminal coronary angioplasty; CABG = coronary artery bypass graft.

With modern techniques and devices (stents, perfusion balloons, intra-aortic balloon pumps), however, events for which emergency surgery is deemed necessary are rare. ${ }^{112}$ Attempts have been made to screen patients into those at low or high risk for complications for which emergency CABG would be necessary. ${ }^{106107}$ Between $9 \%$ and $46 \%$ of those undergoing emergency CABG after PTCA had evidence of acute myocardial infarction despite surgical intervention. ${ }^{2113}$ Surgery may, however, have limited the size of the infarct sustained.

The confusing variation in expert opinion is encapsulated in a number of guideline statements. The British Cardiac Society in 1991 recommended that "in carefully selected patients it is ethical to attempt PTCA in the absence of immediate surgical standby". ${ }^{16}$ In 1992 the British Cardiovascular Intervention Working Party concluded that "on-site surgery is the strongly preferred option". ${ }^{112}$ However, they felt that PTCA can be safely performed without on site cover provided reliable transfer arrangements exist. By contrast in the United States the 1988 ACC/AHA guidelines recommend that "An experienced cardiovascular surgical team should be available within the institution for emergency surgery for all angioplasty procedures", a view shared by the International Society and Federation of Cardiology. ${ }^{17}$ The recent introduction of stenting has now led to a reduction in the need for emergency surgery.

Clearly a balance must be drawn between possible symptomatic improvements gained by making PTCA more accessible at units distant from surgical cover and the safety of undertaking PTCA in such settings. The evidence to approach this more rationally is simply not available at present and constitutes an important area for further work. A pragmatic approach adopted in some localities ${ }^{108}$ has been to permit PTCA within a travelling time area equivalent to that required for a surgical team to prepare.

A similar debate surrounds the performance of diagnostic angiography. ${ }^{1114} \mathrm{~A}$ recent review for the North Western Regional Health Authority concluded that "local catheter laboratory initiatives in district general hospitals should be discouraged on the grounds of possible litigation in the absence of on-site surgery, service standard erosion and sub-optimal use of an expensive facility". ${ }^{115}$ Several case series report anecdotal benefits from on site surgical back-up. ${ }^{11116}$ The UK confidential enquiry into cardiac catheterisation complications reported a mortality rate of $0 \cdot 12 \%$ and $0.08 \%$ of subjects underwent emergency CABG. ${ }^{117}$

The development of new, non-invasive means of delineating coronary artery disease may in due course make these arguments of historic interest. ${ }^{118}$ In the meantime coronary angiography is increasingly being performed in district hospitals, and increasingly on a day case basis. ${ }^{1119120}$ The report of the Cardiac Speciality Service Review Group ${ }^{121}$ expected that district hospitals in the Thames health regions would in the near future be performing $30 \%$ of all angiographies. Strong positive relationships between outcomes and throughput were found consistently in an American literature review. ${ }^{122}$ Optimal outcome requires several hundred cardiac catheterisations per year. It has been recommended in fact that tertiary centres should undertake 1500-2850 catheter investigations per year, and secondary centres $800-1400 .^{121}$

The two broadly competing approaches either a small number of high volume cardiac catheterisation laboratories with on site surgical standby or a larger number of lower volume centres largely without on site standby - carry distinctive advantages and disadvantages from the patients', professionals', and overall NHS perspective (see table 2 ).

\section{Summary and conclusions}

Management strategies for the invasive management of IHD are developing rapidly and a number of important randomised controlled trials have provided only interim results. ${ }^{123}$ Some of the newer angioplasty techniques are being assessed in randomised controlled trials, ${ }^{25-28}$ but so rapid are developments that it is unlikely that the results from these trials will be applicable to the technologies in use when they are reported. All summaries of existing evidence are necessarily interim. It is important that purchasers should not purchase new technologies unless they form part of a randomised evaluation. 
PTCA and CABG offer improved relief over medical treatment for the distress, though not necessarily the disability, caused by angina. PTCA does not offer improved survival or symptom relief over CABG. Short term costs of PTCA are lower, although it has not been shown to be more cost effective than CABG. Use of these procedures should be concentrated upon the more severe grades of angina unrelieved by optimum drug treatment. Within these grades there are those, who can only be identified by angiographic delineation of vessel involvement, upon whom CABG confers improved survival. Use of PTCA and CABG will therefore depend partly upon whether the primary target is improved survival or relief of distress. The "preferred outcome" for angina patients needs to be more clearly defined. Choices need to be made and a balance struck between the goals of reduced premature mortality, reduced frequency of pain and distress from angina, the probability of further intervention, and the ability to return to work. Patients should be informed of the relative benefits and disadvantages of CABG and PTCA, where either procedure is indicated, to enable them to make fully informed choices.

Under certain circumstances it seems likely that the advantages to patients of decentralised coronary angiography and PTCA services are outweighed by their disadvantages in terms of reduced quality and safety. These circum- stances occur either when surgical support is beyond a reasonable distance or when only low throughput is possible. It is unlikely that operators in a district based service with a throughput below several hundred cases would be able to maintain satisfactory levels of expertise and familiarity with changing equipment. Professional bodies have produced a series of guidelines on this matter and these should generally be adhered to.

Further research is required in a number of areas. These include a pressing need for a pragmatic randomised controlled trial comparing patients with similar angina scores randomised either to receive early angiography and subsequent interventions or be managed expectantly. Further randomised controlled trials are also required to compare CABG and modern medical management of angina in those for whom CABG has not already been shown to prolong life. Finally, angiographic investigation should not be made more widely available until the indications for further intervention have been agreed and the necessary capacity to perform CABGs established.

The authors thank the following for comments on early drafts of the report from which this paper is drawn. Dr I Baker, Bristo and District Health Authority; Dr M Williams and Ms J Coast, Health Care Evaluation Unit, University of Bristol; Professor J Hampton, University of Nottingham; Dr P Hubner, The Edenfield Hospital, Leicester; Mr J Hutter, United Bristol Healthcare Trust.

Appendix

(A) Randomised controlled trials (RCT) comparing percutaneous transluminal coronary angioplasty (PTCA) with coronary artery bypass graft (CABG) published since 1992

\begin{tabular}{|c|c|c|c|}
\hline $\begin{array}{l}\text { Study reference, } \\
\text { duration and setting }\end{array}$ & Design & Main findings & Comment \\
\hline $\begin{array}{l}\text { RITA }^{29} \\
2.5 \text { year follow up, } \\
\text { UK }\end{array}$ & $\begin{array}{l}\text { (a) RCT } n=1011 \\
\text { (b) Mean age } 57 ; 19 \% \text { women } \\
\text { (c) } 1,2 \text {, or } 3 \text { vessel disease in patients } \\
\text { in whom revascularisation achievable by } \\
\text { either procedure } \\
\text { (d) } 59 \% \text { grade III or IV angina; } 45 \% \\
\text { single vessel disease } \\
\text { (e) Stable and unstable angina, } 7 \% \text { had } \\
\text { no angina }\end{array}$ & $\begin{array}{l}\text { (a) Mortality similar in CABG } 18(3.6 \%) \text { and } \\
\text { PTCA } 16(3.1 \%) \text {. Mortality and AMI: CABG } 43 \\
\text { (8.6\%) PTCA } 50(9 \cdot 8 \%) \\
\text { (b) Required revascularisation, died or had MI: } \\
\text { CABG } 11 \% \text {; PTCA } 38 \% \text { p<0.001 } \\
\text { (c) Angina at } 2 \text { years: CABG } 22 \% \text {; PTCA } 31 \% \text {. } \\
\text { p<0.007 } \\
\text { (d) No difference in employment status, } \\
\text { breathlessness, physical activity at } 2 \text { years }\end{array}$ & $\begin{array}{l}\text { (a) CABG performed sooner than under } \\
\text { typical NHS conditions. } \\
\text { (b) Only } 3 \% \text { of all patients undergoing } \\
\text { angiography eligible }\end{array}$ \\
\hline
\end{tabular}

\section{EAST $^{33}$}

Emory angioplasty

versus surgery trial

3 year follow up

(a) Single centre RCT $\mathrm{n}=392.26 \%$

vomen; mean age 62

(b) $80 \%$ angina grade III/IV; $60 \% 2$ vessel, $40 \% 3$ vessel disease. $72 \%$ with greater than $50 \%$ stenosis of the left anterior descending artery (c) Enrolment ended 1990

ERACI ${ }^{30}$ 1 year follow up, Argentina (a) RCT $\mathrm{n}=127$

(b) Multiple vessel diseas $(70 \%+$ obstruction in more than one major artery) suitable for either $\mathrm{CABG}$ or PTCA

(c) $85 \%$ male; mean age 58 years

(d) Stable and unstable (83\%) angina

BARI $^{125}$

United States and

(a) RCT $n=2400$ to be enrolled from 1988 .

(b) Multiple vessel disease in whom

either procedure could be applied

(c) $60 \%+$ stenosis of two or more

vessels

(d) No asymptomatic patients (a) Mortality at 3 years: CABG $6 \cdot 2 \%$; PTCA $7 \cdot 1 \%$ (b) Death, $Q$ wave AMI, or large filling defect on thallium scan: CABG 27.3\% PTCA $28.8 \%$ (NS)

(c) Required repeat revascularisation at 3 years: CABG $13 \%$ required PTCA, $1 \%$ required CABG; PTCA $22 \%$ required CABG

required repeat PTCA $(p<0.001)$
(d) Angina at 3 years: CABG $12 \%$ PTCA $20 \%$

(d) Angina at 3 years: CABG 12\% PTCA 20\%

$(p=0.04)$. Taking of antiangin
$51 \% ;$ PTCA $66 \%(p=0.005)$

$51 \%$; PTCA $66 \%(\mathrm{p}=0.005)$
(e) No difference in exercise capacity or employment status

(a) No difference in mortality at 1 year $(\mathrm{CABG}=$ 3; PTCA = 3) or periprocedural $M$ (b) 1 year freedom from cardiac events: $\mathrm{CABG}$ 83.5\%; PTCA $63.7 \%$ p $<0.005$

(a) $16.5 \%$ of patients screened were eligible; only half of these patients agreed to participate in the trial

(a) Small numbers

(b) Unstable angina significantly more frequent in $\mathrm{CABG}$ group at entry (c) $40 \%$ of patients with indications for revascularisation fulfilled entry criterea. $O$ these $42 \%$ were randomised

No findings reported at time of writing. 
$\mathrm{GABI}^{31}$

1 year follow up, German angioplasty bypas investigation (a) 8 centre $\mathrm{RCT} \mathrm{n}=359$. Mean age 58 ; $21 \%$ women

(b) Symptomatic (<or = grade II angina) multi-vessel disease in which either procedure technically feasible (c) $44 \%$ patients 2 vessel disease; $56 \% 3$ essel disease

(d) Median delay between randomisation and treatment PTCA 19 days; CABG 53 days

Goy et al $1994^{32}$ 2 year follow up, Switzerland

(a) RCT $\mathrm{n}=134$

(b) Mean age 54 (CABG); 57 (PTCA $20 \%$ women)

(c) Stable angina associated with isolated proximal left anterior descending artery stenosis $(50 \%$ stenosis)

(d) $78 \%$ grade III or IV angina

RCT multiple vessel disease

$\mathrm{CABRI}^{7}$ (a) Mortality at 12 months: CABG $5 \cdot 1 \%$; PTCA $2 \cdot 2 \%$ (NS). Mortality and AMI at 12 month CABG $13.6 \%$; PTCA $6.0 \%(p=0.017)$ (b) Required repeat revascularisation at 1 year: CABG $6 \%$; PTCA $44 \%(\mathrm{p}<0.001)$

c) Angina at 1 year: CABG $26 \%$; PTCA $29 \%$ (NS); Significantly more PTCA patients required antianginal medication $(88 \%$ v $78 \% \mathrm{p}=0.04)$ (d) No difference in capacity to exercise PTCA $0(0 \%)$

(b) Required revascularisation or had AMI: CABG $8 \%$; PTCA $37 \% \mathrm{p}<0.01$

(c) Angina at 2 years: CABG 11\%; PTCA 23\%

(d) At 2 years PTCA patients took significantly more anti anginal drugs (a) Enrolment to the study terminated early because the primary clinical endpoint (freedom from angina) showed no difference between the groups at 1 yea (b) Four of the deaths in the CABG arm of the trial occurred before surgery (c) Only $4 \%$ of patients screened were eligible for inclusion in the tria (d) Significantly more patients in the CABG arm had their LAD artery revascularised

(a) Small numbers

(b) $9 \%$ of patients randomised to $\mathrm{CABG}$ underwent PTCA rather than CABG

(c) Only $8 \%$ of patients with single vessel disease were eligible

No results available at time of writing

$\mathrm{AMI}=$ acute myocardial infarction

(B) Non-randomised comparisons between percutaneous transluminal coronary angioplasty (PTCA) and coronary artery bypass graft (CABG) published since 1992

Weintraub et al (a) Retrospective observational cohort

$1993^{72}$

5 year follow up,

United States

$n=454$ CABG; 415 PTCA

(b) 2 vessel disease undergoing elective

CABG or PTCA 1984-5

(c) Mean $50 \%+$ stenosis in 2 major coronary vessels

O'Keefe et al $1993 \quad n=100$ CABG matched for age, sex,

(a) Retrospective observational cohort;

up, United States multivessel PTCA. Interventions undertaken in 1985-88

(b) Multiple vessel disease $50 \%+$ stenosis of two or more vessels

(c) Ejection fraction $\leq 40 \%$

(d) Patients with AMI excluded

(e) Mean age 65 years; $78 \%$ male

Vacek et al $1992^{74}$ Mean 2 year follow up for PTCA; $2 \cdot 5$ years for CABG United States

(a) Prospective observational cohor $n=152$ PTCA; $n=134$ CABG Operated upon 1986-89

(b) Prtients with multiple vessel disease having either $3+$ bypasses or $2+$ dilation's to major arteries

(c) Mean age 65 years; $77 \%$ male

Hartz et al $1992^{75}$ Max follow up 2

years, United

(a) Registry study: retrospective

observational cohort $n=25423$ PTCA

$\mathrm{n}=71243$ CABG. Small subgroup

( $n=2931$ revascularisations) examined in detail

(b) All patients in US undergoing these procedures and billed by Medicare 198 and random sample of these

(c) No patients with cardiac arrest of

AMI preprocedure included

(d) Risk adjustments for comorbidities,

cardiac function, coronary anatomy,

severity of angina, sex, age (a) 5 year survival: CABG: $89 \%$; PTCA: $93 \%$ NS

No difference in risk adjusted survival

(b) Additional revascularisation required at 5

years: CABG: $7 \%$; PTCA $43 \% \mathrm{p}<0.0001$

(c) Little difference in proportion with angina at 6 years (CABG 28\%; PTCA 25\%)

(a) 5 year survivial PTCA: $67 \%$; CABG: $76 \%$ NS (b) In hospital death or stroke or both: CABG $12 \%$; PTCA $3 \%(\mathrm{p}=0.03)$

(c) 5 year freedom from disabling angina: $\mathrm{CABG}$ $99 \%$; PTCA $89 \% \mathrm{p}=0.01$

(d) Hospital length of stay: CABG $12 \cdot 8$ days;

PTCA $4 \cdot 3$ days

(e) Repeat revascularisation: CABG $0 \%$; PTCA

$50 \%(\mathrm{p}<0.001)$ (f) Early results favour PTCA, late survival
favours CABG (a) Mortality (2-2.5 years): CABG $14 \%$; PTCA

(b) 2 year AMI rate: CABG 2\%; PTCA 4\%

(c) Angina free: CABG $87 \%$; PTCA $78 \%$ p $<0.02$

(d) Repeat angiography: CABG 10\%; PTCA $49 \%$ (e) In PTCA group 30\% required repeat PTCA and $23 \%$ required $C A B G$. In CABG $4 \%$ had these interventions

(a) After eliminating patients admitted with AMI Mortality CABG: day $305 \cdot 1 \%$, 1 year $10 \cdot 8 \%$ PTCA: 30 day $1.9 \%$, 1 year $6.0 \%$; Risk adjusted mortality for CABG vs PTCA $1.72(0.9$ for high risk subgroup)

(b) Post procedure mortality much higher than

reported in published series

,

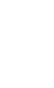

AMI = acute myocardial infarction; $\mathrm{LMCA}=$ left main coronary artery

1 Hillborne LH, Leape LL, Kahan JP, Park RE, Kamberg CJ, Brook RH. Percutaneous transluminal cornary anCJ, Brook RH. Percutaneous transluminal cornnary an-
gioplasty: a literature review and ratings of appropriateness
and necessity. RAND, Santa Monica 1991

2 Leape LL, Hilborne LH, Kahan JP, Stason WB, Park RE, Kamberg CJ, Brook RH. Cornary artery bypass graft: $a$ literature review and ratings of appropriateness and necessity. RAND, Santa Monica 1991.

3 Office of Health Economics. Compendium of Health Statistics 1992. London: Office of Health Economics, 1993.

4 Shaper AG, Cook DG, Walker M, Macfarlane PW. Prevalence of ischaemic heart disease in middle aged British men. Br Heart $\mathcal{F}$ 1984;51:595-605.

5 White A, Nicolaas G, Foster K, Browne F, Carey S. Health survey for England 1991. HMSO, London 1993.

6 Thom TJ. International mortality from heart disease: rates and trends. Int $\mathcal{F}$ Epidemiol 1989;18(3):S20-8.

7 Goldman L. Cost-effectiveness perspectives in coronary heart disease. Am Heart $\mathcal{7}$ 1990;119:733-9.

8 Department of Health. Key area handbook: coronary heart disease and stroke. HMSO, London 1993 .

9 King's Fund Concensus Development Conference ing's Fund Concensus Development Conference Panel.

10 Repont of a work bypass grafting. BMF 1984;289:1527-9. Report of a working group of the BCS: Carcio

11 Hubner PJ. Cardiac interventional procedure in the United
Kingdom during 1990. The British Cardiovascular Intervention Society. Br Heart f 1992;68:343-6.

12 Clinical Standards Advisory Group. Access to and avail ability of comnary artery bypass grafting and coronary angioplasty. HMSO, London 1993.

13 van den Brand $M$. Utilization of coronary angioplasty and cost of angioplasty disposables in 14 western European countries. European Angioplasty Survey Group. Eur Heart f 1993;14:391-7.

14 Morin JE, Symes JF, Guerraty AJ, Poirier NL, Sampalis J. Coronary artery bypass profile in Canada and the United States. Can 7 Cardiol 1990;6:319-22.

15 Higginson LA, Cairns JA, Keon WJ, Smith ER. Rates of cardiac catheterization, coronary angioplasty and opencardiac catheterization, coronary angioplasty and open-
146:921-5.

16 Coronary angioplasty in the United Kingdom. Report of a Working Party of the British Cardiac Society. Br Heart F 1991;66:325-31.

17 Ryan T, Faxon D, Gunnar R, et al. Guidelines for percutaneous transluminal coronary angioplasty. A report of the American College of Cardiology/American Heart Association Task Force on Assessment of Diagnostic and Therapeutic Cardiovascular procedures (Subcommittee on Percutaneous Transluminal Coronary Angioplasty). $\mathcal{F}$ Am Coll Cardiol 1988;12:529-45. 
18 Gray D, Hampton JR, Berstein SJ, Kosecoff J, Brook RH. Audit of coronary angiography and bypass surgery. Lancet 1990;335:1317-20

19 Leape LL, Hilborne LH, Park RE, et al. The appropriateness of use of coronary artery bypass graft surgery in New York State. $7 A M A$ 1993;269:753-60.

20 Hilborne LH, Leape LL, Berstein SJ, et al. The appropriateness of use of percutaneous transluminal coronary angioplasty in New York State. $\mathcal{F} A M A$ 1993;269. $761-5$

21 Berstein SJ, Hilborne LH, Leape LL, et al. The ap propriateness of use of coronary angiography in New York State. $7 A M A$ 1993;269:766-9

22 Rees MR, Michalis LK. Vibrational angioplasty in chronic total occlusions. Lancet 1993;342:999-1000.

23 Eigler NL, Weinstock B, Douglas JS, et al. Excimer laser angioplasty of aorto-ostial stenoses. Circulation 1993; 88(1):2049-57.

24 Topol EJ. Rotablator to the rescue. Am $\mathcal{F}$ Cardiol 1993;71 $858-9$.

25 Fischman DL, Leon MB, Baim DS, et al. A randomised comparison of coronary-stent placement and balloon angioplasty in the treatment of coronary artery disease. $N$ Engl f Med 1994;331:496 501.

26 Serruys PW, de Jaegere P, Kiemeneij F, Macaya C, Rutsch W, Heyndrickx G, Emanuelsson $H$. A comparison of balloon-expandable-stent implantation with balloon angioplasty in patients with coronary artery disease. $N$ Eng 于 Med 1994;331:489 95

27 Topol EJ, Leya F, Pinkerton CA, et al. A comparison of directional atherectomy with coronary angioplasty in patients with

28 Adelman AG, Cohen EA, Kimball BP et al A comparison of directional atherectomy with balloon angioplasty for of directional atherectomy with balloon angioplasty for lesions of the left anterior descen

29 Coronary angioplasty versus coronary artery bypass surgery: the randomised intervention treatment of angin (RITA) trial. Lancet 1993;341:573-80

30 Rodriguez A, Boullon F, Perez-Ballino N, Paviotti C, Liprandi M, Palacios I. Argentine randomised trial of percutaneous transluminal coronary angioplasty versus coronary artery bypass surgery in multivessel disease (ERACI): in-hospital results and 1-year follow-up. $7 A m$ Coll Cardiol 1993;22:1060-70.

31 Hamm CW, Reimers J, Ischinger T, et al. A randomised study of coronary angioplasty compared with bypass surgery in paticnts with symptomatic multivessel coronary gery in paticnts with symptomatic multivess
disease. $N$ Engl f Med 1994;331:1037-43.

32 Goy J, Eeckhout E, Burnand B, et al. Coronary angioplasty versus left internal mammary artery grafting for isolate proximal left anterior descending artery stenosis. Lance 1994:343:1449-53.

33 King SB, L mbo NJ, Weintraub WS, Kosinski AJ, Barnhar HX. A randomised trial comparing coronary angioplasty with coronary bypass surgery. $N$ Engl f Med 1994;331: 1044-50.

34 European Coronary Surgery Study Group. Prospective randomised study of coronary artery bypass surgery in stable angina pectoris: a progress report on survival. Circulation 1982;65:II67-71.

35 Coronary Artery Bypass Study Group. Coronary artery surgery study (CASS): a randomised trial of coronary artery bypass surgery. Survival data. Circulation 1983;68: artery bypa $939-50$.

36 Murphy ML, Hultgren HN, Detre K, Thomsen J, Takaro $\mathrm{T}$. Treatment of chronic stable angina. A preliminary report of survival data of the randomized VA cooperative study. $N$ Engl f Med 1977;297:621-7.

37 Dougenis D, Naik S, Brown AH. Is repeated coronary surgery for recurrent angina cost effective? Eur Heart 1992;13:9-14

38 Kolettis TM, Miller HC, de Bono DP. Coronary angioplasty in patients with prior coronary artery bypass grafting. Int $\mathcal{f}$ Cardiol 1990;28:333-9.

39 Salomon NW, Page US, Bigelow JC, Krause AH, Okies JE, Metzdorff MT. Reoperative coronary surgery. Comparative analysis of 6591 patients undergoing primary parative analysis of 6591 patients undergoing primary bypass and 508 patients undergoing reoperative coronary

artery bypass. 7 Thorac Cardiovasc Surg 1990;100:250-9.
40 Grines CI, Browne KF, Marco J, et al. A comparison of immediate angioplasty with thrombolytic therapy for immediate angioplasty with thrombolytic therapy for Myocardial Infarction Study Group. N Engl f Med 1993; Myocardial

41 Zijlstra F, de Boer MJ, Hoorntje JC, Reiffers S, Reiber JH Suryapranata $\mathrm{H}$. A comparison of immediate coronary angioplasty with intravenous streptokinase in acute myocardial infarction. N Engl f Med 1993;328:680-4.

42 Gibbons RJ, Holmes DR, Reeder GS, Bailey KR, Hopfenspirger MR, Gersh BJ. Immediate angioplasty compared with the administration of a thrombolytic agen followed by conservative treatment for myocardial infarction. The Mayo Coronary Care Unit and Cath-
eterization Laboratory Groups. N Engl f Med 1993;328: 685-91.

43 Pringle SD, Boon NA. Immediate coronary angioplasty for acute myocardial infarction. $B M 7$ 1993;306:1489-90.

44 Yusuf S, Zucker D, Peduzzi P et al. Effect of coronary artery bypass graft surgery on survival: overview of 10 year results from randomised trials by the Coronary Artery Bear results from randomised trials by the Coronary Artery Bypass Surg
$563-70$.

45 European Coronary Surgery Study Group. Long term results of prospective randomised study of coronary artery bypass surgery in stable angina pectoris. European Coronary Surgery Study Group. Lancet 1982;ii:1173-80.

46 Varnauskas E. Twelve year follow up survival in the randomised European coronary surgery study. $N \mathrm{Engl} f \mathrm{Med}$ $1988 \cdot 319 \cdot 332-7$.

47 Varnauskas E. Survival, myocardial infarction, and employment status in a prospective randomised study of coronary bypass surgery. Circulation 1985;72(V):90-101

48 Rogers WJ, Coggin CJ, Gersh BJ, et al. Ten-year followup of quality of life in patients randomized to receive medical therapy or coronary artery bypass graft surgery. The coronary artery surgery study (CASS). Circulation 1990;82:1647-58.

49 Alderman EL, Bourassa MG, Cohen LS, et al. Ten-year follow-up of survival and myocardial infarction in the randomized coronary artery surgery study. Circulation 1990;82:1629-46.

50 Killip T, Passamani E, Davis K. Coronary Artery Surgery Study (CASS): a randomised trial of coronary bypass surgery. Eight years follow up and survival in patient with reduced cjection fraction. Circulation 1985;72(V): 102 .

51 Coronary Artery Surgery Study (CASS). A randomised trial of coronary artery bypass surgery. Quality of life in patients randomly assigned to treatment groups. Cir culation 1983;68:951-60.

52 Coronary Artery Surgery Study (CASS). Myocardial in farction and mortality in the coronary artery surgery study (CASS) randomised trial. N Engl f Med 1984;310:750-8

53 Tikaro T, Hultgren HN, Lipton MJ, Detre KM. The VA cooperative randomized study for coronary arteria occlusive disease. II Subgroup with significant left main lesions. Circulation 1975;54(suppl 3(6))(III):107-17.

54 The VA Coronary Artery Bypass Surgery Cooperative Study Group. Eighteen-year follow-up in the veterans affairs cooperative study of coronary artery bypass surgery affairs cooperative study of coronary artery bypass

55 Peduzzi P, Hulgren H, Thomsen J, Detre K. Ten-year effect of medical and surgical therapy on quality of life: veterans administration cooperative study of coronary artery surgery. Am f Cardiol 1987;59:1017-23.

56 Detre K, Takaro T, Hulgren $\mathrm{H}$, et al. Long term mortality and morbidity results of the veterans administration randomised trial of coronary artery bypass surgery. Circulation 1985;72(V):84 9

57 Peduzzi P, Detre K, Murphy ML, Thomsen J, Hultgren $H$, Takaro $T$. Ten-year incidence of myocardial infarction and prognosis after infarction. Department of Veteran affairs cooperative study of coronary artery bypass surAffairs cooperative study of coronar

58 Luchi R, Scott S, Deupree R. Comparison of medical and surgical treatment for unstable angina pectoris. Results of a veterans administration cooperative study. $N$ Engl $\mathscr{f}$ Med 1987;316:977-8

59 Sharma GV, Deupree RH, Khuri SF, Parisi AF, Luchi RJ Scott SM. Coronary bypass surgery improves survival in high-risk unstable angina. Results of a veterans administration cooperative study with an 8-year follow-up. Veterans Administration Unstable Angina Cooperative Study Group. Circulation 1991;84(III):260-7.

60 Parisi A, Khuri S, Deupree R, Sharma G, Scott M, Luch RJ. Medical compared with surgical management of un stable angina. Circulation 1989;80:1176-89.

61 Russell RO, Moraski RE, Kouchoukos N. Unstable angin pectoris: national cooperative study group to compare pectoris: national cooperative study group to compare
medical and surgical therapy. $A m$ f Cardiol $1978 ; 42$ : 839-48.

62 Booth DC, Deupree RH, Hultgren HN, DeMaria AN Scott SM, Luchi RJ. Quality of life after bypass surgery for unstable angina. Circulation 1991;83:87-95.

63 Seldon R, Neill WA, Ritzmann LW, Okies JE, Anderson RP. Medical versus surgical therapy for acute coronary insufficiency. $N$ Engl 7 Med 1975;293:1329-33.

64 Laarman GJ, Kiemeneij F, van der Wieken LR, Tijssen JGP, Suwarganda JSM, Slagboom T. A pilot study of coronary angioplasty in outpatients. Br Heart $\mathcal{f} 1994 ; 72$ $12-15$

65 Landau C, Lange RA, Hillis LD. Percutaneous transluminal coronary angioplasty. $N$ Engl f Med 1994;330 luminal $981-93$.

66 Stammen F, De Scheerder I, Glazier JJ, et al. Immediate and follow-up results of the conservative coronary angioplasty strategy for unstable angina pectoris. $A m$ gioplasty strategy for un

67 Myler RK, Shaw RE, Stertzer SH, et al. Lesion morphology and coronary angioplasty: current experience and anaand coronary angioplasty: current experienc

68 Hollman J, Simpfendorfer C, Franco I, Whitlow P, Goormastic $M$. Multivessel and single-vessel coronary angioplasty: a comparative study. Am Heart $\mathcal{F}$ 1992;124 9-12.

69 Hamad N, Pichard AD, Lyle HRP. Results of percutaneous transluminal coronary angioplasty by multiple, relativel low frequency operators: 1986-1987 experience. $A m$ Cardiol 1988;61:1229-31.

70 Parisi AF, Folland ED, Hartigan P. A comparison of angioplasty with medical therapy in the treatment of single-vessel coronary artery disease. Veterans Affairs ACME Investigators. N Engl 7 Med 1992;326:10 6.

71 BARI, CABRI, EAST, GABI and RITA. Coronary angioplasty on trial. Lancet 1990;335:1315-6.

72 Weintraub WS, King SB, Jones EL, et al. Coronary surgery and coronary angioplasty in patients with two-vessel coronary artery disease. Am $\mathcal{f}$ Cardiol 1993;71:511-7. 
73 O'Keefe JHJ, Allan JJ, McCallister BD, et al. Angioplasty versus bypass surgery for multivessel coronary artery disease with left ventricular ejection fraction $\leq 40 \%$. $A m \mathcal{F}$ Cardiol 1993;71:897-901.

74 Vacek JL, Rosamond TL, Stites HW, et al. Comparison of percutaneous transluminal coronary angioplasty versus coronary artery bypass grafting for multivessel coronary artery disease. Am f Cardiol 1992;69:592-7.

75 Hartz AJ, Kuhn EM, Pryor DB, et al. Mortality after coronary angioplasty and coronary artery bypass surgery (the national Medicare experience). Am 7 Cardiol 1992; 70:179-85.

76 Mick MJ, Simpfendorfer C, Arnold AZ, Piedmonte M, Lytle BW. Early and late results of coronary angioplasty and bypass in octogenarians. Am F Cardiol 1991;68:131620.

77 Webb JG, Myler RK, Shaw RE, et al. Bidirectional crossover and late outcome after coronary angioplasty and bypass surgery: 8 to 11 year follow-up. $f \mathrm{Am}$ Coll Cardiol 1990;16:57 65 .

78 Allen JK, Fitzgerald ST, Swank RT, Becker DM. Functional status after coronary artery bypass grafting and percutaneous transluminal coronary angioplasty. $\mathrm{Am} \mathcal{F}$ Cardiol 1990;66:921-5.

79 Wong JB, Sonnenberg FA, Salem DN, et al. Myocardial revascularization for chronic stable angina: analysis of percutaneous transluminal coronary angioplasty based on data available in 1989. Ann Intern Med 1990;113 85271 .

80 Holmes DRJ, Garratt KN, Topol EJ. Coronary angioplasty versus excisional atherectomy trial: CAVEAT (editorial). Int $\mathcal{F}$ Cardiol 1992;35:143-6.

80a Elliot JM, Berdan LG, Holmes DR et al. One year follow up in the coronary angioplasty versus excusional atherectomy trial (CAVEAT I). Circulation 1995;91:2158-2166.

81 Buchwald A, Unterberg C, Werner G, Voth E, Kreuzer H, Wiegand V. Initial clinical results with the Wiktor stent: a new balloon-expandable coronary stent. Clin Cardiol a new balloon-ext

82 Lincoff AM, Topol EJ, Chapekis AT, et al. Intracoronary stenting compared with conventional therapy for abrupt vessel closure complicating coronary angioplasty: a matched case-control study. F Am Coll Cardiol 1993;21: 866-75

83 Leon MB, Wong SC. Intracoronary stents. A breakthrough or just another small step? Circulation 1994;89:1323-7.

84 Cohen DJ, Breall JA, Ho KKL, Kuntz RE, Goldman L, Baim DS, Weinstein MC. Evaluating the potential costeffectiveness of stenting as a treatment for symptomatic single-vessel coronary disease. Circulation 1994;89:1859 74 .

85 Sculpher MJ, Seed P, Henderson RA, Buxton MJ, Pocock SJ, et al. Health service costs of coronary angioplasty and SJ, et al. Health service costs of coronary angioplasty and
coronary artery bypass surgery: the randomised incoronary artery bypass surgery: the randomised in-
tervention treatment of angina (RITA) trial. Lancet 1994; tervention treat

86 Finkler S. The distinction between costs and charges. Ann Intern Med 1982;96:102-9.

87 Charles ED, Wayne JD, Oberman A, et al. Costs and benefits associated with treatment for coronary artery disease. Circulation 1982;66(III):87-90.

88 Hemenway D. Comparative costs versus symptomatic and employment benefits of medical and surgical treatment of stable angina. Med Care 1985;23(2):133-41.

89 van den Brand $M$, van Halem $C$, van den Brink $F$, et al. Comparison of costs of percutaneous transluminal coronary angioplasty and coronary bypass surgery for patients with angina pectoris. Eur Heart $\mathcal{f}$ 1990;11:76571 .

89a Cohen DJ, Bicall JA, Ho KK. Economics of elective coronary revascularisation. $\mathcal{f}$ AM Coll Cardiol 1993;22:

90 Jang G, Block P, Cowley M, et al. Relative cost of coronary angioplasty and bypass surgery in a one vessel disease model. Am $f$ Cardiol 1984;53:52C-5C.

91 Black AJR. Comparative costs of percutaneous transluminal coronary angioplasty and coronary artery by-pass grafting in multivessel coronary artery disease. $\mathrm{Am} f$ Cardiol 1988;62:809-11.

92 Kelly M, Taylor G, Moses H, et al. Comparative cost of myocardial revascularisation: Percutaneous transluminal angioplasty and coronary artery bypass surgery. $\mathcal{F} \mathrm{Am} \mathrm{Coll}$ Cardiol 1985;5:16-20.

93 Reeder G, Krishan I, Nobrega F, et al. Is percutaneous angioplasty less expensive than bypass surgery? $N$ Engl $\mathcal{F}$ Med 1984;311:1157-62.

94 Hlatky MA, Lipscomb J, Nelson C, et al. Resource use and cost of initial coronary revascularization. Coronary angioplasty versus coronary bypass surgery. Circulation 1990;82(IV):208-13.

95 Berreklouw E, Hoogsteen J, van Wandelen R, et al. Bilateral mammary artery surgery or PTCA or multiple vessel coronary artery disease? Eur Heart $\mathcal{f}$ 1989;10 (suppl H): $61-70$

96 Wittels EH, Hay JW, Gotto AMJ. Medical costs of coronary artery disease in the United States. Am $\mathcal{F}$ Cardiol 1990 65:432-40
97 Goodman C. The role of percutaneous transluminal coronary angioplasty in cornary revascularisation: evidence, assessmen and policy. The Swedish Council on Technology Asand policy. The Swedish Council

98 Mason J, Drummond M, Torrance G. Some guidelines on the use of cost-effectiveness league tables. BMF 1993

99 Williams A. Economics of coronary artery bypass grafting $B M F$ 1985;291:326-9.

100 Weinstein MC, Stason WB. Cost effectiveness of coronary artery bypass surgery. Circulation 1982;66(supplIII):56 66.

101 Baim DS, Kuntz RE. Coronary angioplasty. Is surgical standby needed? FAMA 1992;268:780-1.

$102 \mathrm{Vogel} \mathrm{JH}$. Changing trends for surgical standby in patient undergoing percutaneous transluminal coronary angioplasty. Am $\mathrm{f}$ Cardiol 1992;69:25F-32F.

103 Parker DJ. Does angioplasty need on site surgical cover? A surgeron's view. Br Heart f 1990;64:1-2.

104 Shaw TR. Does angioplasty need on site surgical cover? A physician's view. Br Heart $\mathcal{F}$ 1990;64:3-4

105 Cameron DE, Stinson DC, Greene PS, Gardner TJ. Surgical standby for percutaneous transluminal coronary angioplasty: a survey of patterns of practice. Ann Thorac Surg 1990;50:35-9.

106 Iniquez A, Macaya C, Hernandez R, et al. Comparison of results of percutaneous transluminal coronary angioplasty with and without selective requirement of surgical standby. Am f Cardiol 1992;69:1161-5.

107 Meier B, Urban P, Dorsaz PA, Favre J. Surgical standby for coronary balloon angioplasty. $\mathcal{F} A M A \quad 1992 ; 268$ $741-5$.

108 Shaw TRD, Starkey IR, Essop AR, et al. Emergency coronary bypass surgery after vessel occlusion at angioplasty in centres without on site facilities for cardiac surgery. Br Heart 7 1989;6:438A.

109 Richardson SG, Morton P, Murtagh JG, O'Keeffe DB, Murphy P, Scott ME. Management of acute coronary occlusion during percutaneous transluminal coronary angioplasty: experience of complications in a hospital with out on site facilities for cardiac surgery. BMF 1990;300 355-8.

110 Klinke WP, Hui W. Percutaneous transluminal coronary angioplasty without on-site surgical facilities. $A m$ f Cardiol 1992;70:1520-5.

111 Powney JG, Bonser RS, Lentini S. Emergency coronary artery surgery after refractory cardiac arrest: a single centre experience. Br Heart f 1992;67:392-4.

112 The Council of the British Cardiovascular Intervention Society. Surgical cover for percutaneous transluminal coronary angioplasty. Br Heart 7 1992;68:339-41.

113 Levy RD, Bennett DH, Brooks NH. Desirability of immediate surgical standby for coronary angioplasty. $B r$ Heart 7 1991:65:68-71.

114 Mills P. Should coronary angiography be performed in district hospitals? Br Heart $\mathcal{F}$ 1990;63:73.

115 Heagerty AM. Cardiology health care in the North Western Region, 1993.

116 Stewart JT, Gray HH, Ward DE, Pumphrey CW, Redwood DR, Parker DJ. Major complications of coronary arteriography: the place of cardiac surgery. Br Heart $\mathcal{F} 1990$; 63:74 7 .

117 de Bono D. Complications of diagnostic cardiac catheterisation: results from 34401 patients in the United Kingdom confidential enquiry into cardiac catheter comKingdom confidential enquiry into cardiac
plications. Br Heart $\mathcal{F}$ 1993;70:297-300.

118 Manning WJ, Li W, Edelman RR. A preliminary report comparing magnetic resonance coronary angiography with conventional angiography. $N$ Engl f Med 1993;328: 828-32

119 Christie LG, Carlson KL, Michels LG, Liberty SW. Costeffectiveness and safety of inpatient versus outpatient coronary angiography. Circulation 1985;72(4):401.

120 Clark DA, Moscovich MD, Vetrovec GW, Wexler L Guidelines for the performance of outpatient catheterization and angiographic procedures. Cathet Cardiovasc Diagn 1992;27:5-7.

121 London Implementation Group. Report of the Cardiac Specialty Review Group. HMSO, London 1993.

122 Luft HS, Garnick DW, Mark DH, McPhee SJ. Hospital volume, physician volume and patient outcomes: assessing the
evidence. Ann Arbor MI, Health Administration Press evidence. Ann Arbor MI, Heal

123 Landau C, Faxon D. Acroyms in angioplasty and restenosis: a summary of recent and ongoing clinical randomised trials. Fournal of Interventional Cardiology 1992; 5:29-37.

124 Maynard A. Developing the health care market. Economic fournal 1991;101:1277-86.

125 BARI participants. Protocol for the bypass angioplasty revascularisation investigation. Circulation 1991;84(suppl V):V1-V27

126 Hillman BJ, Joseph CA, Marby MR, Sunshine JH, Kennedy SD, Noether $M$. Frequency and costs of diagnostic imaging in office practice- a comparison of self referring and radiologist-referring physicians. $N$ Engl f Med 1990; 323: $1604-8$. 